\title{
Annalisa Azzoni, Matthew W. Stolper. "From the Persepolis Fortification Archive Project, 5 : The Aramaic Epigraph ns(y)h on Elamite Persepolis Fortification Documents"
}

\section{Rémy Boucharlat}

\section{OpenEdition}

\section{Journals}

Édition électronique

URL : http://journals.openedition.org/abstractairanica/47307

DOI : 10.4000/abstractairanica.47307

ISBN : 1961-960X

ISSN : 1961-960X

\section{Éditeur :}

CNRS (UMR 7528 Mondes iraniens et indiens), Éditions de l'IFRI

\section{Référence électronique}

Rémy Boucharlat, «Annalisa Azzoni, Matthew W. Stolper. "From the Persepolis Fortification Archive Project, 5 : The Aramaic Epigraph ns(y)h on Elamite Persepolis Fortification Documents" », Abstracta Iranica [En ligne], Volume 37-38-39 | 2018, document 95, mis en ligne le 30 décembre 2018, consulté le 26 septembre 2020. URL : http://journals.openedition.org/abstractairanica/47307 ; DOI : https:// doi.org/10.4000/abstractairanica.47307

Ce document a été généré automatiquement le 26 septembre 2020

Tous droits réservés 


\title{
Annalisa Azzoni, Matthew W. Stolper. "From the Persepolis Fortification Archive Project, 5 : The Aramaic Epigraph ns(y)h on Elamite Persepolis Fortification Documents"
}

\author{
Rémy Boucharlat
}

\section{RÉFÉRENCE}

Annalisa Azzoni, Matthew W. Stolper. "From the Persepolis Fortification Archive

Project, 5 : The Aramaic Epigraph ns(y)h on Elamite Persepolis Fortification

Documents", Arta 2015.004, 88 p. http://www.achemenet.com/pdf/arta/

ARTA_2015.004-Azzoni-Stolper.pdf

Environ deux cent cinquante exemplaires, parmi les milliers de tablettes en cunéiforme élamite-achéménide de la Fortification de Persépolis, portent une très courte inscription en araméen tracé à l'encre au pinceau dans un espace libre de texte ou bien par-dessus l'empreinte de sceau. Pour ce type d'inscriptions, connu chez les NéoAssyriens et en Babylonie des VIe-IVe s. av.n.è., qui pourrait signifier reçu ou bordereau, les $\mathrm{A}$. proposent d'adopter le terme très général de epigraph. La plupart de ces tablettes avec surcharge correspondent à des mouvements de produits ou bien des journaux récapitulant des entrées et sorties d'objets et de biens (les tablettes de Persépolis sont réparties en plus de 20 catégories, reçus, bordereaux, rations, journaux, dépôts, échanges, etc). Un terme attesté par près d'un tiers des tablettes inscrites en araméen est $n s h$ ou, nsyh, terme dérivé d'une racine araméenne. Les A. proposent de traduire le mot par « copié » « remplacé par » dans le sens où les textes en cunéiforme 
sur tablettes de terre étaient ensuite reproduits en araméen sur parchemin ; le terme attesterait que l'opération a été achevée.

\section{AUTEURS}

\section{RÉMY BOUCHARLAT}

UMR 5133 CNRS-Université de Lyon 